\title{
Evaluation of silanes in SBR 1502 / Telinne Monspessulana flour composites
}

\author{
Oscar Buitrago ${ }^{1 *}$, Oscar Palacio ${ }^{1}$ and Emilio Delgado ${ }^{1}$ \\ ${ }^{1}$ Facultad de Ingeniería, Universidad Militar Nueva Granada, Bogotá D.C., Colombia \\ *oscar.buitrago@unimilitar.edu.co
}

\begin{abstract}
A comparative study was performed on the effect of the addition of silane coupling agents (SCA), vinyltrimethoxysilane (VTMS) and 3-aminopropyltriethoxysilane (APTES) to a mixture of styrene butadiene rubber SBR1502 with Telinne Monspessulana flour (TMF). SCA was directly added into the mixture using untreated and mercerized TMF. Also, TMF and SBR1502 mixing trials were conducted with the TMF previously mercerized and injected with each of the silanes. The rubber compounds were subjected to tensile tests in order to evaluate the coupling power of both SCA. It was found that the vinyl silane type produced the best results in the tensile strength.
\end{abstract}

Keywords: composite, natural fiber, SBR1502, silanes.

\section{Introduction}

Using natural fibers or wood flour as a potential filler to, at least partially, replace mineral fillers for the production of polymeric compounds is important because of the benefits offered by plant fibers. These include the fact that their low density allows the development of lighter compounds, that they are non toxic, they are biodegradable, their production can be sustainable, and they are less abrasive, increasing the service life of machinery.

SBR styrene butadiene rubber is an elastomer, widely used in the manufacture of items such as tires, hoses, footwear, packing, conveyor belts, mats, and others ${ }^{[1]}$.

There are also numerous studies that examine the effect of incorporating natural fiber with SBR rubber. For example, Kumar et al. ${ }^{[2]}$ analyzed the rheological behavior of SBR1502 compounds with sisal fiber, finding that these acquire pseudo-plastic behavior upon chemical treatments owing to the strong interfacial adhesion between the fibre and the rubber matrix. Wang et al blended 50 parts of SBR1502 with 50 parts of linear low density polyethylene (LLPE) with rice husks and used maleic anhydride (MA) as a compatibilizer. The mechanical properties were optimal when the concentration of MA was 2.5 parts per hundred of rubber (phr). They also mention that when more than $25 \mathrm{phr}$ of rice husk was used, the dielectric properties of the composite decreased ${ }^{[3]}$. Kumar and Thomas ${ }^{[4]}$ analyzed SBR 1502 compounds with sisal fibers, finding that the tensile strength and tear resistance improved when the fiber orientation was longitudinal and its size was $6 \mathrm{~mm}$ in length. They also mention that the optimal concentration of sisal fiber was $35 \mathrm{phr}$.

Regarding the use of silanes to improve compatibility of natural fiber with SBR, Wang et al mixed Si69 silane with SBR 1502 and $20 \mathrm{phr}$ of silica, varying the concentration of hemp flour. Adding the flour improved the vulcanization conditions, and imparted stiffness and toughness to the compound, although the excess in flour concentration leads to decrease of these mechanical properties ${ }^{[5]}$.

Generally, natural fibers are subjected to mercerization as a prelude to treatment with type SCA cupping agents; $\mathrm{NaOH}$ treatment allows the $\mathrm{OH}$ groups of cellulose to be exposed directly and thus better fiber-SCA coupling can be achieved. The grafted fiber is then mixed with the polymer ${ }^{[6,7]}$. The coupling agent can also be added directly during the mixing of the fiber with the polymer ${ }^{[8]}$.

It is important to note that any SBR compound must be cross-linked with sulfur (vulcanization), using peroxide or radiation in order to increase mechanical, chemical and thermal resistance to the respective compound ${ }^{[9-12]}$.

In our research, we analyzed the effect of the incorporation of VTMS and APTES on composites prepared with untreated SBR1502 + TMF, SBR1502 + mercerized TMF and SBR1502 + grafted TMF with SCA. By measuring the tensile properties and hardness, we comparatively evaluated the coupling effect of both silanes.

\section{Materials and Methods}

\subsection{Materials}

The following materials were used:

Telinne Monspessulana flour with a particle diameter of 400-800 $\mu \mathrm{m}$ and a humidity of $0.20 \%$. Rubber: SBR 1502 manufactured by INSA ${ }^{\circledR}$ S.A. Mexico. Coupling Agents: APTES YACA $110^{\circledR}$ of $98.41 \%$ purity produced by Nanjing Lanya Chem ${ }^{\circledR}$. Co. Ltd., VTMS Struktol ${ }^{\circledR}$ SCA 971 of $>98.6 \%$ purity manufactured by Struktol ${ }^{\circledR}$. Processing aid: Struktol ${ }^{\circledR}$ WB16 of Struktol ${ }^{\circledR}$. Antioxidant: Irganox ${ }^{\circledR}$ 1076 manufactured by $\mathrm{BASF}^{\circledR}$. Cross-linking agent DCP Perkadox ${ }^{\circledR}$ BC FF, purity $99 \%$, produced by Akzo Nobel ${ }^{\circledR}$. 


\subsection{Methods}

\subsubsection{Experimental design}

Seven (7) tests were conducted with the base formula as seen in Table 1. All quantities remained constant.

The "Control" test was defined for the compound of SBR1502 with TMF, untreated and free of SCA. Two (2) modes of silane addition were tested: 1) direct addition of SCA during mixing of SBR1502 with TMF with no surface treatment.

Direct addition of SCA during the mixing of SBR1502 with mercerized TMF. 2) Pretreatment of mercerized TMF with SCA and later mixing with SBR1502 (see Table 2). The tensile properties of the silane were measured to assess its ability to couple the flour and the rubber.

\subsubsection{Surface treatment TMF}

Mercerization: Telinne Monspessulana flour was mercerized in $\mathrm{NaOH}$ solution at $8 \%$ for 4 hours at $35^{\circ} \mathrm{C}$, according to the methodology used by Buitrago et al. ${ }^{[13]}$.

Graft silane-TMF: The flour previously mercerized was grafted with silane. The amount of SCA was $10 \%$ based on the weight of TMF. Silane was pre-hydrolyzed for one hour, the time of TMF immersion was 4 hours and drying was performed at $45^{\circ} \mathrm{C}$ for 24 hours. The above procedure was performed for the APTES and VTMS following the methodology used by Buitrago et al. ${ }^{[13]}$.

\subsubsection{Preparation of compounds}

Compounding: The preparation of the mixture was performed in a roller mill with a capacity of $600 \mathrm{~cm}^{3}$. The SBR1502 was placed on rollers until band formation. Then, immediately, $1 / 3$ of the total TMF was added, next the SCA was added (see Table 2). TMF continued to be added slowly. When the incorporation of the flour was completed, the processing aid and antioxidant were added. The DCP was added three (3) minutes before the end of the stage. The compounding temperature was $115 \pm 5{ }^{\circ} \mathrm{C}$; the processing time was 13 minutes.

Compression molding: We used a hydraulic press heated by electrical resistance. Mold dimensions: $17 \mathrm{~cm} * 17 \mathrm{~cm}$ and $3.6 \mathrm{~mm}$ of thickness.
The operating parameters were: mold temperature $160 \pm 1{ }^{\circ} \mathrm{C}, 5.24 \mathrm{MPa}$ of specific pressure, pressing time of 6 minutes.

\subsubsection{Methods of analysis}

Gel Percentage: It quantifies the degree of crosslinking of the compound. It was determined following the indications of ASTM D 2765-01, method $\mathrm{A}^{[14]}$. It is interesting to observe that soxhlet extraction diluted the non-cross-linked polymer, although it swelled the rubber compound. To determine the final weight, the samples that were subjected to extraction were dried at $50^{\circ} \mathrm{C}$ for 4 hours. Subsequently they were cooled in liquid nitrogen for 24 hours, then they were pulverized and heated again at $80^{\circ} \mathrm{C}$ for 4 hours to remove the solvent. The sample calculation is shown in the Equation 1.

$$
\% G E L=\left[\left(W_{F}-f * W_{I}\right) /(1-f) * W_{I}\right] * 100
$$

$W_{F}$ and $W_{I}$ represent, respectively, the final and initial weight of the rubber compound, and $f$ is the fraction of fiber in the composite.

Tensile tests: The specimen type B was used according to ASTM D412-06a standard ${ }^{[15]}$. The tests were performed on a universal machine Shimadzu ${ }^{\circledR}$ AGS-X. Test Parameters: travel speed of $50 \mathrm{~mm} / \mathrm{min}$, temperature $24^{\circ} \mathrm{C}$, and relative humidity $45 \%$. Five specimens were used for each formulation.

Hardness: Hardness was determined according to ASTM D2240-05 standard ${ }^{[16]}$ at $24{ }^{\circ} \mathrm{C}$ and $45 \%$ of relative humidity. INSIZE ${ }^{\circledR}$ durometer of A type was used. Five (5) measurements were performed for each test.

SEM: The fractured surface of the specimens under tensile strength were observed by scanning electron microscopy (SEM), the procedure was performed following the methodology used by Tobón et al. ${ }^{[17]}$.

\section{Results and Discussions}

\section{$3.1 \mathrm{Gel}$ content}

In Figure 1 an increase is observed in the percentage of gel when incorporating the SCA compared to the control, regardless of the means of addition.

Table 1. General formulation (all amounts in phr).

\begin{tabular}{cccccc}
\hline SBR 1502 & TMF $^{*}$ & Antioxidant & Processing aid & DCP & SCA** \\
\hline 100 & 25 & 1 & 1 & 1 & 1 \\
\hline
\end{tabular}

*Untreated / mercerized / grafted (see Table 2); ${ }^{* * V T M S ~ o r ~ A P T E S ~ i n ~ d i r e c t ~ a d d i t i o n ~ t o ~ t h e ~ m i x t u r e ~(s e e ~ T a b l e ~ 2) . ~}$

Table 2. Description of tests.

\begin{tabular}{ccc}
\hline SCA & $\begin{array}{c}\text { Surface Treatment } \\
\text { TMF }\end{array}$ & Method of incorporating the SCA \\
\hline Control & & Without silane \\
\hline VTMS & Without treatment & Direct addition of the SCA into the compound mixture \\
\hline APTES & Mercerized & Direct addition of the SCA into the compound mixture \\
\hline VTMS & Mercerized & Surface treatment of graft SCA with fiber before mixing \\
\hline VTMS & &
\end{tabular}


This could mean that there was no competition between the silane coupling reactions with the flour and the crosslinking reaction of the polymer chains with $\mathrm{DCP}^{[17-19]}$. When comparing the two silanes difference in values was observed between them, it shows that the percentage of gel APTES was higher independent of the method of addition.

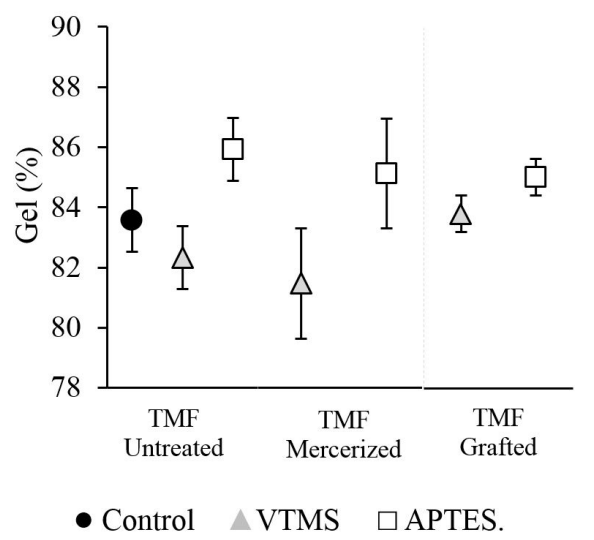

Figure 1. \% of Gel in SBR1502 compounds.

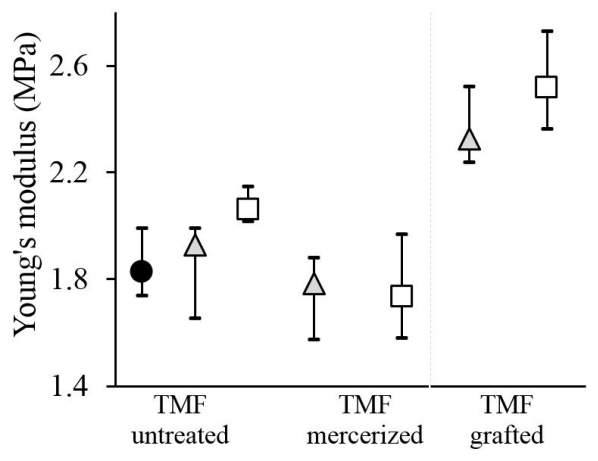

- Control $\triangle$ VTMS $\square$ APTES.

Figure 2. Young's modulus for SBR1502 compounds.

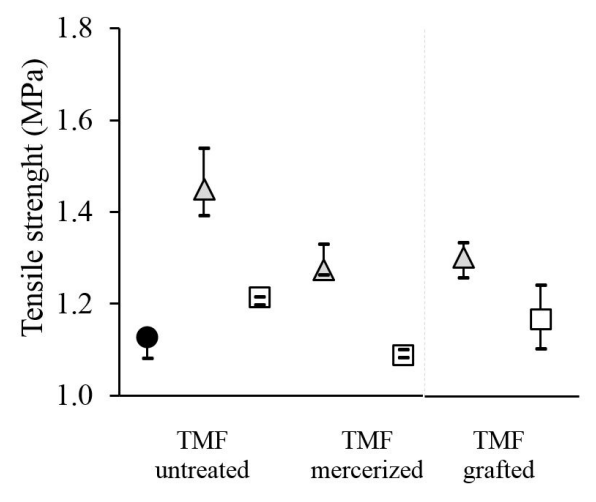

- Control $\triangle$ VTMS $\square$ APTES.

Figure 3. Tensile strength for SBR1502 compounds.

\subsection{Young's modulus}

The modulus of elasticity was significantly higher in composites prepared with fiber previously grafted with APTES and VTMS silanes, with an increase in the modulus of elasticity of $28 \%$ and $37 \%$, respectively, compared to the control (see Figure 2). These results in the modulus match the trends of other studies of hemp and wood with silane coupling agents ${ }^{[7,20-22]}$ where the modulus of elasticity improved because the presence of the coupling agent allowed a more uniform dispersion in the rubber matrix allowing a strong interfacial bonding with fiber. The direct addition of the silanes did not significantly affect the modulus of elasticity regardless of the fiber treatment. Comparatively, it was not observed that the silane type influenced the Young's modulus.

\subsection{Tensile strength}

In Figure 3 the tensile strength results are presented. The incorporation of APTES as a coupling agent did not affect the values of tensile strength compared to the control, while the incorporation of VTMS increased tensile strength regardless of the mode of addition; the maximum value was obtained with direct addition using untreated flour and was $30 \%$ higher compared to the control, due to the improvement of the transfer of stress in particle-polymer interface ${ }^{[20,22]}$.

The other compounds, which have VTMS, increased traction by $15 \%$ compared to the control.

The above results support the conclusion that the vinyl type silane VTMS has superior performance compared to APTES in composites prepared with SBR1502. It is shown that mercerized flour affected the tensile strength negatively in both silanes when these were added directly to the mixture. This phenomenon may be attributed in particular to the conditions used in the mercerization process, where the concentration of $\mathrm{NaOH}$ at $8 \%$ could possibly generate the presence of large amounts of $\mathrm{Na}^{+}$ions, which could in turn cause interference in the coupling ${ }^{[23]}$.

\subsection{SEM fractography analysis}

All SEM images show dark layers (SBR matrix), the wood flour particle is white; also voids formed by the release of the particle when breaking the specimen in the tensile test are observed.

Variation is observed in the shape and size of wood flour, for example many are below the nominal specification written at the beginning of the experimental part $(400-800 \mu \mathrm{m})$. This is because subsequent reduction or breaking of the particles during the shear mixing step.

There are morphological differences in fracture zones of some specimens, specifically on the surface of the wood particle. The SEM image of the composite VTMS With TMF-untreated (Figure 4a), has filament formation which corresponds to the formation of grafts between natural fiber and polymer, which is consistent because this specimen showed the highest value tensile strength (Figure 3 ).

Similarly in Figure $4 \mathrm{~b}$ forming grafts shown in APTES with TMF-untreated compound, precisely this specimen showed the highest tensile strenght value when the amino silane is used. 
No evidence of grafting is evident in the specimens where the silanes were added to the previously mercerized wood flour (Figure 4b,c), this is consistent as the results of tensile strength were low.

The SEM of specimens of wood flour previously grafted with silanes (Figure 5a, b) have different morphology compared to the control (Figure 6). It was observed that the particles have surface modification, but this change was not sufficient to achieve grafting between the particle with SBR matrix.

\subsection{Elongation at break}

Figure 7 shows no significant difference between both silanes. The compounds prepared with APTS yielded lower values compared to the control, confirming that the
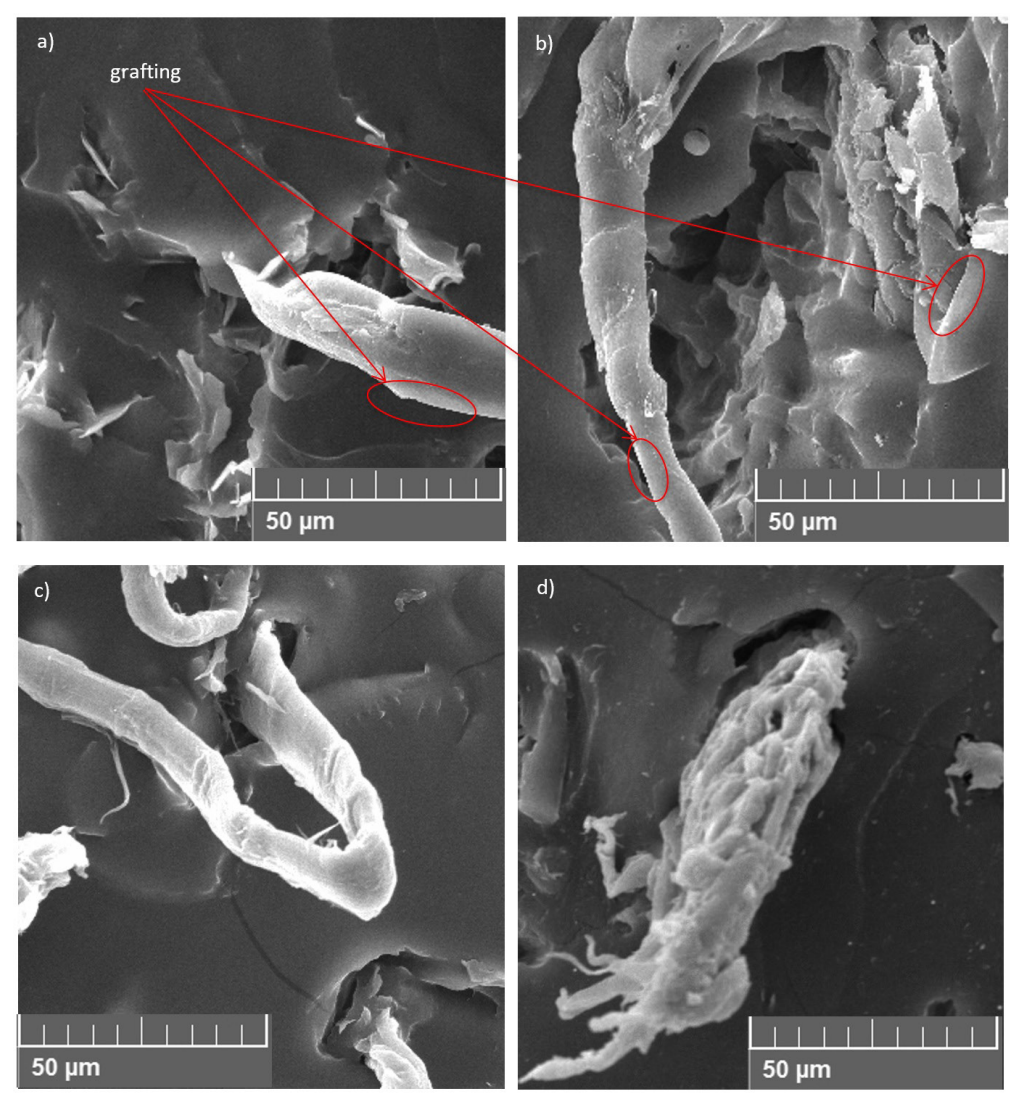

Figure 4. SEM 1000x. Fractography of specimens. Direct adition of silanes. (a) VTMS-TMF untreated; (b) APTES-TMF untreated; (c) VTMS-TMF mercerized; (d) APTES-TMF mercerized.
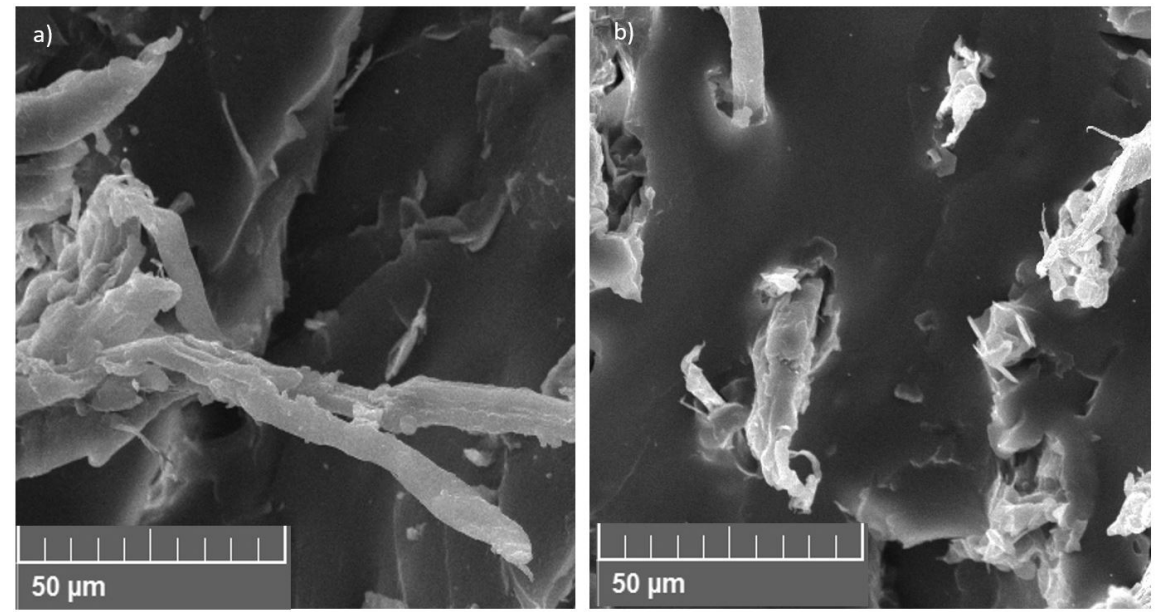

Figure 5. SEM 1000x. Fractography of specimens TMF grafted with silane, (a) VTMS; (b) APTES. 


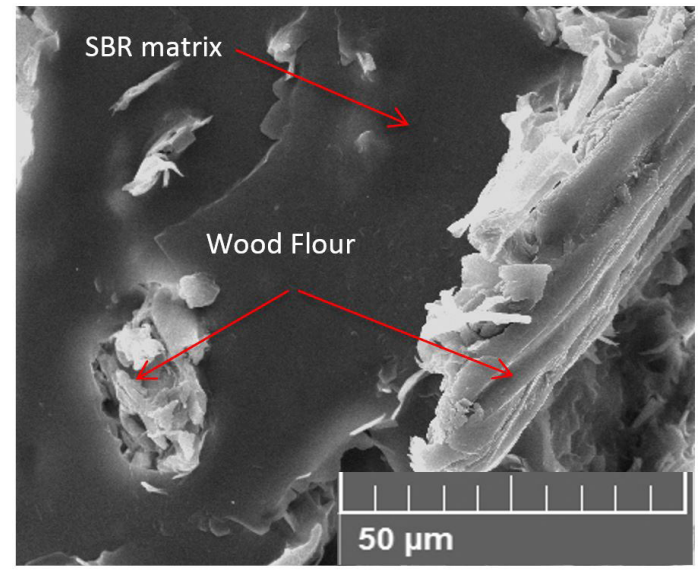

Figure 6. SEM 1000x. Fractography specimen control.

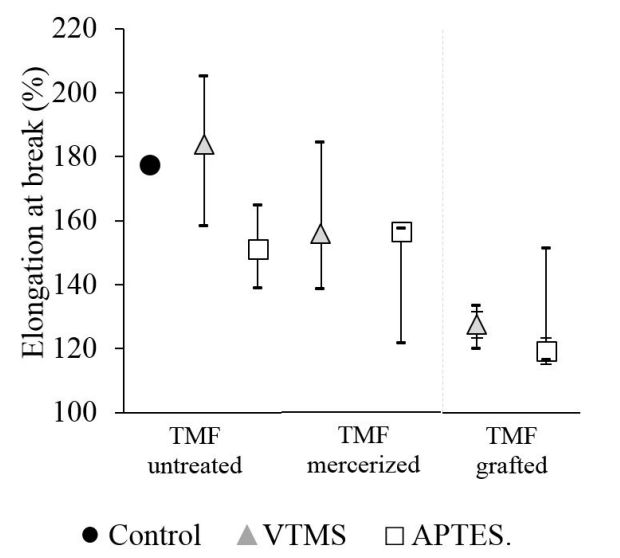

Figure 7. Elongation at break of SBR1502 compounds.

addition of the amino type silane does not contribute to the coupling between TMF with SBR1502. It is also noted that the compound prepared with VTMS grafted fiber was lower compared to the forms of addition.

\subsection{Energy at break}

The results of the energy required to break rubber compounds with TMF indicate that it is not possible to determine any significant differences in all of the tests (Figure 8).

\section{7 Hardness}

The results of hardness tests are seen in Figure 9; the compounds made with VTMS have a slight increase in hardness compared to the control. The maximum increase in hardness was achieved by the compound prepared with fiber grafted with APTES and VTMS. The addition of silanes can in some way increase the hardness, which is consistent with other studies into chitosan and sisa[ ${ }^{[7,20,21]}$. There is a relationship of hardness to elastic modulus, the highest hardness values also have greater Young's modulus (Figure 2).

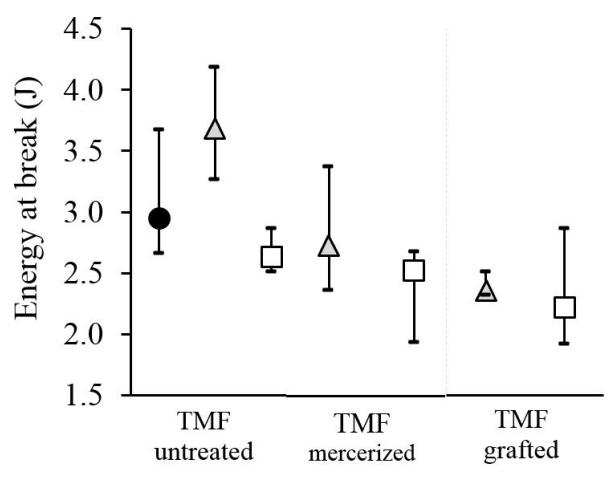

- Control $\triangle$ VTMS $\square$ APTES.

Figure 8. Energy at break for SBR1502 compounds.

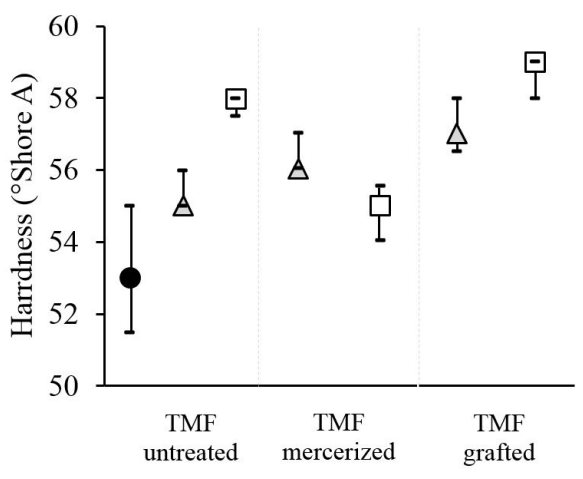

- Control $\triangle$ VTMS $\square$ APTES.

Figure 9. Hardness for SBR1502 compounds.

\section{Conclusions}

Adding silanes did not decrease the percentage of gel; it was not possible to identify interference between the coupling reaction and cross-linking; comparatively gel percentage was higher in the compounds having APTES that VTMS.

VTMS and APTES improve tensile strength in SBR-wood flour composites, the vinyl silane produced the highest values. It is possible that the presence of the double bond of the vinyl group contributed to the formation of bonds with the fiber surface and rubber. This silane is recommended by the manufacturer for coupling silica type loads with SBR1502.

When the silanes were added directly on SBR-wood flour untreated, yielded values greater of tensile strength compared to other modes of incorporation, which is confirmed by the observation of grafting on surface particle through of SEM images.

It was expected that mercerization of the fiber would help to improve the coupling of the vegetable flour with rubber, especially with VTMS silane. This did not happen, possibly due to the conditions used in the mercerization. 
APTES amino type silane increased rigidity and hardness, but no positive effect was observed on tensile strength.

Further studies are recommended to treat TMF mercerizing, specifically by varying the concentration of $\mathrm{NaOH}$. In the SEM images can be seen a change in morphology of wood flour mercerized vs untreated, but these effects did not ensure coupling between with SBR matrix.

\section{Acknowledgements}

This study is derived from the project INV-ING-1547 sponsored by "Vicerrectoria de Investigaciones de la Universidad Militar Nueva Granada" - One year term 2014.

\section{References}

1. Mark, J. E. (1999). Polymer Data Handbook. Oxford: Oxford University Press.

2. Kumar, R. P., Nair, K. C. M., Thomas, S., Schit, S. C., \& Ramamurthy, K. (2000). Morphology and melt rheological behaviour of short-sisal-fibre-reinforced SBR composites. Composites Science and Technology, 60(9), 1737-1751. http:// dx.doi.org/10.1016/S0266-3538(00)00057-9.

3. Khalf, A. I., \& Ward, A. (2010). Use of rice husks as potential filler in styrene butadiene rubber/linear low density polyethylene blends in the presence of maleic anhydride. Materials \& Design, 31(5), 2414-2421. http://dx.doi.org/10.1016/j.matdes.2009.11.056.

4. Kumar, R. P., \& Thomas, S. (1995). Short fibre elastomer composites: effect of fibre length, orientation, loading and bonding agent. Bulletin of Materials Science, 18(8), 1021-1029. http://dx.doi.org/10.1007/BF02745189.

5. Wang, J., Wu, W., Wang, W., \& Zhang, J. (2011). Preparation and characterization of hemp hurd powder filled SBR and EPDM elastomers. Journal of Polymer Research, 18(5), 10231032. http://dx.doi.org/10.1007/s10965-010-9503-4.

6. Fuqua, M., Huo, S., \& Ulven, C. A. (2012). Natural Fiber Reinforced Composites. Polymer Reviews, 52(3), 259-320. http://dx.doi.org/10.1080/15583724.2012.705409.

7. Changjie, Y., Zhang, Q., Junwei, G., Junping, Z., Youqiang, S., \& Yuhang, W. (2011). Cure characteristics and mechanical properties of styrene-butadiene rubber/hydrogenated acrylonitrile-butadiene rubber/silica composites. Journal of Polymer Research, 18(6), 2487-2494. http://dx.doi.org/10.1007/ s10965-011-9670-y.

8. Maldas, D., Kokta, B. V., \& Daneault, C. (1989). Influence of coupling agents and treatments on the mechanical properties of cellulose fiber-polystyrene composites. Journal of Applied Polymer Science, 37(3), 751-775. http://dx.doi.org/10.1002/ app.1989.070370313.

9. Basfar, A. A., Abdel-Aziz, M., \& Mofti, S. (2002). Influence of different curing systems on the physico-mechanical properties and stability of SBR and NR rubbers. Radiation Physics and Chemistry, 63(1), 81-87. http://dx.doi.org/10.1016/S0969806X(01)00486-8.

10. Nabil, H., Ismail, A., \& Azura, R. (2014). Properties of natural rubber/recycled ethylene-propylene-diene rubber blends prepared using various vulcanizing systems. Iranian Polymer Journal, 23(1), 37-45. http://dx.doi.org/10.1007/s13726-0130197-4.

11. Changjie, Y., Zhang, Q., Junwei, G., Junping, Z., Youqiang, S., \& Yuhang, W. (2011). Cure characteristics and mechanical properties of styrene-butadiene rubber/hydrogenated acrylonitrile-butadiene rubber/silica composites. Journal of Polymer Research, 18(6), 2487-2494. http://dx.doi.org/10.1007/ s10965-011-9670-y.

12. Shih, R.-S., Kuo, S.-W., \& Chang, F.-C. (2011). Thermal and mechanical properties of microcellular thermoplastic SBS/PS/ SBR blend: effect of crosslinking. Polymer, 52(3), 752-759. http://dx.doi.org/10.1016/j.polymer.2010.12.026.

13. Buitrago, O., Delgado, A., \& Aperador, W. (2014). Surface treatment of straight Retamo Liso (Telinne monspessulana) by silane coupling agents (SCA). Ciência e Técnica Vitivinícola, 29(12), 11-23.

14. American Society for Testing and Materials-ASTM. (2001). ASTM D2765-01: standard test methods for determination of gel content and swell ratio of crosslinked ethylene plastics. West Conshohocken: ASTM.

15. American Society for Testing and Materials-ASTM. (2013). ASTM D412-06a: standard test methods for vulcanized rubber and thermoplastic elastomers. West Conshohocken: ASTM.

16. American Society for Testing and Materials-ASTM. (2010). ASTM D2240-05: standard test methods for rubber property: durometer hardness. West Conshohocken: ASTM.

17. Tobón, A. E. D., Chaparro, W. A. A., \& Rivera, W. G. (2014). Mejoramiento de las propiedades de tensión en WPC de LDPE: HIPS/fibra natural mediante entrecruzamiento con DCP. Polimeros: Ciência e Tecnologia, 24(3), 291-299. http:// dx.doi.org/10.4322/polimeros.2014.026.

18. Ahmad, E. E. M., \& Luyt, A. S. (2012). Effects of organic peroxide and polymer chain structure on morphology and thermal properties of sisal fibre reinforced polyethylene composites. Composites. Part A, Applied Science and Manufacturing, 43(4), 703-710. http://dx.doi.org/10.1016/j.compositesa.2011.12.011.

19. Mokoena, M. A., Djoković, V., \& Luyt, A. S. (2004). Composites of linear low density polyethylene and short sisal fibres: The effects of peroxide treatment. Journal of Materials Science, 39(10), 3403-3412. http://dx.doi. org/10.1023/B:JMSC.0000026943.47803.0b.

20. Ryu, S. R., \& Lee, D. J. (2007). Effects of short-fiber shape on tensile properties of reinforced rubber. Journal of Materials Science, 42(3), 1019-1025. http://dx.doi.org/10.1007/s10853006-1397-5.

21. Ismail, H., Shaari, S. M., \& Othman, N. (2011). The effect of chitosan loading on the curing characteristics, mechanical and morphological properties of chitosan-filled natural rubber (NR), epoxidised natural rubber (ENR) and styrene-butadiene rubber (SBR) compounds. Polymer Testing, 30(7), 784-790. http://dx.doi.org/10.1016/j.polymertesting.2011.07.003.

22. Wang, J., Wu, W., Wang, W., \& Zhang, J. (2011). Effect of a coupling agent on the properties of hemp-hurd-powder-filled styrene-butadiene rubber. Journal of Applied Polymer Science, 121(2), 681-689. http://dx.doi.org/10.1002/app.33744.

23. Gwon, J. G., Lee, S. Y., Doh, G. H., \& Kim, J. H. (2010). Characterization of chemically modified wood fibers using FTIR spectroscopy for biocomposites. Journal of Applied Polymer Science, 116(6), 3212-3219. http://dx.doi.org/10.1002/ app.31746.

Received: June 19, 2015

Revised: Mar. 21, 2016

Accepted: June 29, 2016 